\title{
Teknolojik Gelişme ve Yüksek Teknoloji İhracatının Ekonomik Karmaşıklık Endeksi Üzerindeki Etkisi: Türkiye Örneği
}

\author{
Ayberk ŞEKER*
}

\begin{abstract}
$\ddot{O} Z$
Ülkelerin uluslararası ticarette rekabet üstünlüğünü elde edebilmeleri için teknoloji yatırımları gerçekleştirmeleri ve yüksek teknolojili ürün ihracatına yönelmeleri büyük önem arz etmektedir. Bu doğrultuda, teknolojik gelişme düzeyinin ihracat üzerindeki etkilerinin ortaya koyulması gerekmektedir. Ekonomik karmaşıklık endeksi, bir ülkenin ihraç ettiği ürünlerin bilgi yoğunluğunu göz önüne alarak bir ekonominin bilgi yoğunluğunu ve üretken çıktısını ölçmektedir. İhracattaki bilgi yoğunluğunu gösteren ekonomik karmaşıklı endeksi, hem ülkelerin ihracatlarındaki teknoloji yoğunluğunu hem de ürün çeşitliliğini ortaya koymaktadır. Çalışma kapsamında ülkelerin uluslararası ticarette rekabet üstünlüğünü ortaya koyan ekonomik karmaşıklı endeksinin teknolojik gelişme, yüksek teknolojili ürün ihracatı ve sermaye yatırımları ile ilişkisi Türkiye için analiz edilmiştir. Johansen ve Gregory-Hansen eşbütünleşme testleri sonucunda, ekonomik karmaşıklı endeksi ile yüksek teknolojili ürün ihracatı, yerli patent başvuruları ve sabit sermaye yatırımları arasında uzun dönemli bir ilişkinin bulunduğu tespit edilmiştir. Daha sonra ise uzun dönemli katsayl tahmini yapılarak ve nedensellik testleri gerçekleştirilerek değişkenler arasındaki ilişki ortaya koyulmuştur. Nedensellik analizleri sonucunda, ekonomik karmaşıklık endeksi, yüksek teknolojili ürün ihracatı ve yerli patent başvuruları arasında çift yönlü bir nedensellik ilişkisi olduğu görülmüşürr. Bununla birlikte, brüt sabit sermaye yatırımlarından ekonomik karmaşıklık endeksi, yüksek teknolojili ürün ihracatı ve yerli patent başvurularına doğru tek yönlü bir nedensellik ilişkisi bulunduğu ortaya koyulmuştur.
\end{abstract}

Anahtar Kelimeler: Ekonomik Karmaşıklık Endeksi, Yüksek Teknolojili Ürün İhracatı, Teknolojik Gelişme, Gregory-Hansen Eşbütünleşme, Granger Nedensellik.

JEL Sinıflandırması: F10, O11, O14, O30.

\section{Impacts of Technological Development and High-Tech Exports on Economic Complexity Index: The Case of Turkey}

\begin{abstract}
Determining sectors invested in is greatly important for countries to gain competitive advantages in international trade.. In this direction, it is beneficial for countries to reveal the effects of the level of technological development on exports. The economic complexity index measures the density of information and the productive output of an economy by considering the knowledge intensity of products that a country exports. The economic complexity index, which shows the intensity of information in exports, reveals both the technological density and the product diversity of countries' exports. In the scope of study, the relationships between high technology exports, technological developments, capital formation and the economic complexity index that reveal the competitive advantage in international trade for Turkey has been analyzed. As a result of Johansen and GregoryHansen cointegration tests, long-term relationships between economic complexity index, high-tech product exports, domestic patent applications and fixed capital investments have been determined.
\end{abstract}

\footnotetext{
* Dr. Öğretim Üyesi, Bursa Teknik Üniversitesi, İTBF, Uluslararası Ticaret ve Lojistik Bölümü. ayberk.seker@btu.edu.tr
} 
Then, long-term coefficients and causality relationships among the variables have been estimated. As a result of causality analysis, bidirectional causality relationship between economic complexity index, high-tech product exports and resident patent applications is seen. On the other hand, unidirectional causality relationships from gross fixed capital investments to economic complexity index, high-tech product exports and resident patent applications are determined.

Keywords: Economic Complexity Index, High-Technology Export, Technological Development, Gregory-Hansen Cointegration, Granger Causality.

JEL Classification: F10, O11, O14, O30.

\section{GíRiş}

Ülkelerin uluslararası ticarette rekabet gücü elde etmek amacıyla hangi sektörlere yöneleceği konusu büyük önem arz etmektedir. Uluslararası rekabette ülkelerin karşılaştırmalı üstünlük elde edebilmeleri için hangi sektörlere yatırım yapmaları gerektiğini, hangi sektörlerde araştırma ve geliştirme faaliyetlerini yoğunlaştıracağını ve hangi sektörlerin uluslararası ticaretine odaklanacağını belirlemeleri gerekmektedir. Özellikle giderek artan küresel ticaret hacmi ile birlikte, ülkeler sürdürülebilir ekonomik büyüme sağlamaları ve kalkınma düzeylerini arttırabilmeleri için daha fazla uluslararası ticarete bağımlı hale gelmiştir.

Ülkelerin uluslararası ticaretlerini ve ekonomik kalkınmalarını sürdürülebilir hale getirmeleri için ihracatlarında katma değerli ve yüksek teknolojili ürün yelpazelerini arttırmaları gerekmektedir. Yüksek teknolojiye sahip ürünlerin ihracatı ile ülkeler hem daha fazla katma değer elde edebilmekte hem de ihracatlarını sürdürülebilir duruma getirmektedirler. $\mathrm{Bu}$ doğrultuda, ülkelerin uluslararası rekabette var olabilmeleri doğrudan ihracatlarında yüksek teknoloji barındıran ürünlerin bulunmasıyla yakından ilişkilidir.

Katma değerli ve yüksek teknolojili ürün ihracatının toplam ihracat içerisindeki payının yükseltilmesi ülkelerin araştırma ve geliştirme faaliyetlerinin yoğunluğuna ve verimliliğine dayanmaktadır. Bu doğrultuda, ülkeler uluslararası rekabette var olabilmek adına yatırımları ile araştırma ve geliştirme faaliyetlerini karşılaştırmalı üstünlük elde edilebilecekleri yüksek teknoloji sektörlerinde gerçekleştirmelidirler. Gerçekleşen teknolojik ilerlemeler ile birlikte, uluslararası rekabet avantajı sağlanarak ihracatta yüksek teknoloji ve katma değer barındıran ürünlerin yelpazesi genişlemiş olacaktır. Bu durum ülkelere küresel ticarette karş1laştırmalı üstünlük avantajı elde etmelerini sağlayacaktır.

Küresel rekabette ülkelerin karşılaştırmalı üstünlük elde etmeleri için bir diğer önemli nokta ise gerçekleştirilen sermaye yatırımlarıdır. Uluslararası rekabet avantajı sağlayabilmek için ülkelerin sermaye yatırımlarını katma değeri yüksek ve teknoloji yoğun alanlara yönlendirmeleri gerekmektedir. İhracata dayalı ekonomik büyümenin sağlanması, ülkelerin ihraç ettikleri ürünlerin hem yüksek katma değere sahip olması hem de ürün çeşitliliğinin fazla olmasına dayanmaktadır. Bu noktada ülkeler, sermaye yatırımlarını yüksek katma değere sahip ve ürün yelpazesinde çeşitliliği sağlayan alanlara yönlendirmeleri gerekmektedir. 


\section{TÜRKIYE'NIN TEKNOLOJIK GELISSME VE YÜKSEK TEKNOLOJILİ ÜRÜN İHRACATI PERFORMANSI}

Günümüzde küreselleşme süreci ile birlikte, uluslararası pazarlarda ülkeler arasındaki rekabet düzeyi de yükselmiştir. Uluslararası rekabet seviyesini etkileyen en önemli faktör, ülkelerin teknolojik gelişme düzeyleridir (Tekin ve Hancıoğlu, 2018: 898). Bununla beraber, ülkelerin ekonomik büyümelerinde ve uluslararas1 ticaretlerinde teknolojik gelişme ve yüksek teknolojili ürün üretiminin önemi de giderek artmıştır (Çütçü, 2017: 586). Ülkeler uluslararası rekabet üstünlüğü elde edebilmek amacıyla araştırma ve geliştirme faaliyetlerine önemli yatırımlar gerçekleştirmekte, böylelikle hem teknolojik gelişme düzeylerini arttırmayı hem de ihracatlarında yüksek teknolojili ürünlerin payını arttırmayı hedeflemektedirler.

Küreselleşen uluslararası pazarlarda, ülkelerin sahip oldukları teknolojik birikimler ve teknolojik gelişme kapasiteleri uluslararası rekabette ve uluslararası ticarette önemli avantajlar ortaya koymaktadır (Di Pietro ve Anoruo, 2006: 134). Teknolojik gelişme ve yüksek teknoloji üretimi, ülkeleri uluslararası ticarette başarılı kılan en önemli faktör haline gelmiştir. Ülkeler sahip oldukları teknolojik kapasiteleri doğrultusunda birbirlerine üstünlük kurmaktadırlar (Şahbaz vd., 2014: 48).

Ülkelerin sahip oldukları yerli patent sayıları, ülke içerisinde gerçekleştirilen buluş ve icat sayılarını yansıtmakta ve araştırma ve geliştirme sisteminin ne kadar etkin işlediğini göstermektedir. Ülkelerin gerçekleştirdiği icat sayılarını gösteren yerli patent sayıları, ülkelerin araştırma ve geliştirme kapasitelerini göstermesi ve araştırma ve geliştirmeye dayalı çıktının ölçülmesini sağlamaktadır. Bununla birlikte, ülkelerin sahip oldukları patent sayıları o ülkenin yenilikçilik potansiyelini de yansıtmaktadır (Ang vd., 2015: 275).

Son yıllarda, gelişmekte olan ülkeler uluslararası rekabette var olabilmek için teknolojik gelişmelerin önemi kavramaya başlamıştır. Bu doğrultuda, teknoloji geliştirmek için çeşitli araştırma ve geliştirme yatırımları gerçekleştirmeye başlanmış ve geliştirdikleri teknolojileri ihraç ederek küresel rekabette yer edinmeye çalışmaktadırlar (Çetin, 2016: 32). Gelişen teknoloji düzeyi, ihraç edilen ürünlerin ekonomiye sağladıkları katma değeri arttırmaktadır. Bu doğrultuda, ülkelerin teknolojik birikim seviyeleri ve teknolojik gelişme düzeyleri arttıkça ihracatını gerçekleştirdikleri ürünlerin değerinin de yükselmesi beklenmektedir.

Teknolojik gelişmeler vasıtasıyla sahip olunan bilgi birikimi, hem ülkelerin üretim süreçlerindeki verimliliği arttırmakta hem de teknoloji yoğun yeni ürünlerin üretimini sağlamaktadır (Yıldırım ve Kesikoğlu, 2012: 167). Bu doğrultuda, yüksek teknolojili ürün üretimi arttıkça verimlilik artışına bağlı olarak ihracattan elde edilecek kazancın da artması beklenmektedir. Bu durum sonucunda, yüksek teknolojili üretim yükseldikçe ekonomik karmaşıklık endeksinin de yükselmesi beklenmektedir.

Falvey (1981) ve Falvey ve Kierzkowski (1987) Heckscher-Ohlin'e dayanarak ortaya koydukları açıklama, sermaye açısından zengin olan ülkelerin yüksek kalitede ürünler ihraç etme oranının yüksek olduğunu, çünkü yüksek kaliteli ürünlerin üretiminin daha yüksek sermaye yoğunluğuna sahip olan ülkelerde 
gerçekleşebileceğini belirtmişlerdir. Bununla birlikte, Flam ve Helpman (1987), kalite farklılıklarının faktör donanımlarındaki farklılıklardan ziyade teknolojik farklılıklardan kaynaklandığını iddia etmektedir. Bu doğrultuda, ülkelerin üretip ihraç ettiği ürünler arasındaki kalite farklılıklarının sahip oldukları teknolojik birikimlerine bağlı olduğu ileri sürülmektedir.

Tablo 1. Türkiye'nin Teknolojik Gelişme, Yüksek Teknolojili Ürün İhracatı ve Brüt Sabit Sermaye Yatırımları Performans1

\begin{tabular}{cccc}
\hline Dönem & $\begin{array}{c}\text { Yerli Patent } \\
\text { Başvurusu }\end{array}$ & $\begin{array}{c}\text { Yüksek Teknolojili Ürün İhracati } \\
\text { (Milyon \$) }\end{array}$ & $\begin{array}{c}\text { Brüt Sabit Sermaye Yattrımları } \\
\text { (Milyar \$) }\end{array}$ \\
\hline $\mathbf{2 0 0 0}$ & 277 & 1077.5 & 64.9 \\
\hline $\mathbf{2 0 0 1}$ & 337 & 990.8 & 36.3 \\
\hline $\mathbf{2 0 0 2}$ & 414 & 536.4 & 50.6 \\
\hline $\mathbf{2 0 0 3}$ & 489 & 763.1 & 70.1 \\
\hline $\mathbf{2 0 0 4}$ & 682 & 1010.8 & 102.1 \\
\hline $\mathbf{2 0 0 5}$ & 928 & 881.8 & 135.5 \\
\hline $\mathbf{2 0 0 6}$ & 1072 & 1281.3 & 163.3 \\
\hline $\mathbf{2 0 0 7}$ & 1810 & 1643.9 & 194.1 \\
\hline $\mathbf{2 0 0 8}$ & 2221 & 1680.7 & 221.1 \\
\hline $\mathbf{2 0 0 9}$ & 2555 & 1359.5 & 148.3 \\
\hline $\mathbf{2 0 1 0}$ & 3180 & 1712.9 & 208.2 \\
\hline $\mathbf{2 0 1 1}$ & 3885 & 1922.1 & 260.3 \\
\hline $\mathbf{2 0 1 2}$ & 4434 & 1978.5 & 247.3 \\
\hline $\mathbf{2 0 1 3}$ & 4392 & 2176.9 & 283.1 \\
\hline $\mathbf{2 0 1 4}$ & 4766 & 2346.6 & 271.2 \\
\hline $\mathbf{2 0 1 5}$ & 5352 & 2323.1 & 243.8 \\
\hline $\mathbf{2 0 1 6}$ & 6230 & 2182.7 & 243.7 \\
\hline $\mathbf{2 0 1 7}$ & 7994 & 3052.4 & 263.7 \\
\hline
\end{tabular}

Tablo 1'de Türkiye'nin yerli patent başvuru sayıları, yüksek teknolojili ürün ihracatı ve brüt sabit sermaye yatırımları yer almaktadır. Yerli patent başvuruları bir ülkede yerleşik bulunan kişilerin yenilik gerçekleştirme düzeyleri hakkında önemli bilgiler içermektedir. Bununla birlikte, Türkiye'nin teknolojik gelişme düzeyini göstermesi açısından önem arz etmektedir. Yıllar itibariyle incelendiğinde, teknolojik gelişmeyi temsilen ele alınan yerli patent başvuru sayılarında önemli derecede artışlar gözlemlenmektedir. Bu durum, teknolojik gelişmeye verilen önem doğrultusunda inovasyon girişimlerinin yükseldiğini ifade etmektedir. Yüksek teknolojili ürün ihracatının da teknolojik gelişmeye paralel bir şekilde yükselme gösterdiği görülmektedir. Küresel ve ulusal ekonomik sorunların görüldüğü yıllar dışında, yüksek teknolojili ürün ihracatının yükselen bir trende sahip olduğu gözlemlenmektedir. Türkiye'nin teknolojik ve ekonomik göstergelerinden bir diğer olan brüt sabit sermaye yatırımlarının da diğer göstergeler gibi ekonomik konjonktürden etkilendiği görülmekte, ancak y1llar itibariyle artış gösterdiği gözlemlenmektedir.

Türkiye'nin teknolojik gelişme, yüksek teknolojili ürün ihracatı ve sermaye yatırımlarına ilişkin gösterdiği gelişmelerin ihracatındaki ürün çeşitliliği ve bilgi 
yoğunluğunun da yükselmesine işaret etmektedir. Bu doğrultuda, Türkiye'nin teknolojik gelişme ve ekonomik performansının ekonomik karmaşıklık endeksi üzerindeki etkilerinin incelenmesi büyük önem arz etmektedir.

\section{EKONOMİK KARMAŞIKLIK ENDEKSİ (ECI)}

Ülkelerin ihracatına konu olan ürünlerin kalitesini ölçmek için Massachusetts Teknoloji Enstitüsü (MIT) tarafindan ürün gruplarına göre Ekonomik Karmaşıklık Endeksi (ECI) geliştirilmiştir. ECI puanına sahip tüm ürünler, HS veya Standart Uluslararası Ticaret Sinıflandırması (SITC) kodları altında sınıflandırılmakta ve ECI hesaplamasında hesaba katılmıs olan faydalı bilgiler dikkate alınmaktadır.

Bir ekonominin sahip olduğu karmaşıklığı, içerisinde yer alan yararlı bilgilerin çokluğu ile ilgilidir. Bireyler bildikleri ile sınırlı kaldıklarından, toplumların bilgi tabanını genişletebilmelerinin tek yolu, bireylerin ürün yapmak için gittikçe karmaşık ağlardaki etkileşimlerini kolaylaştırmaktır. Ekonomik karmaşıklık, ülkelerin üretebilecekleri bu ürünlerin kompozisyonu ile ölçülebilmektedir. Bir ülkenin ekonomik karmaşıklığı, ülkenin üretken çıktısının bileşimi ile ifade edilmekte, bilgiyi tutmak ve birleştirmek için ortaya çıkan yapıları yansitmaktadir.

ECI ayrıca, ülkelerin gelir düzeyi ve gelecek yıllar için olası ülke büyüme oranları hakkında da bazı bilgiler sunmaktadır (Gala vd., 2018). Tüketiciler sadece bir ürünü değil, o ürünün tüm bilgisini de satın alırlar. İş bölümü sayesinde insanlar pazarda uzmanlaşırlar ve bilgi mallardan çok azına ulaşır (Hidalgo \& Hausmann, 2009).

Uluslararası ticarette rekabet gücü, ülkelerin karşılaştırmalı üstünlüğüne bağlıdır. Bu nedenle, ürün çeşitleri ve en çok işlem gören ürünler, ülkenin ticaret kapasitesini tespit etmek için hayati öneme sahiptir. Tablo 2'de HS2 (Uyumlaştırılmış Mal Tanımlama ve Kodlama Sistemi) kapsamında Türkiye'nin ihraç ve ithal mallarını göstermektedir.

Tablo 2. Türkiye' de En Çok Ticareti Gerçekleştirilen Ürünlerin (HS2)

İhracat ve İthalat Payları (2017)

\begin{tabular}{|c|c|c|c|}
\hline \multirow{5}{*}{ İHRACAT } & Tekstil Sektörü (\%18) & \multirow{5}{*}{ İTHALAT } & Makine (\%23) \\
\hline & Taşımacılık (\%18) & & Metal (\%14) \\
\hline & Makine (\%15) & & Taşımacılık (\%11) \\
\hline & Metal (\%12) & & Mineraller (\%9.8) \\
\hline & $\begin{array}{c}\text { Değerli Metal ve Taşlar } \\
(\% 6.3)\end{array}$ & & Kimya (\%9) \\
\hline $\begin{array}{c}\text { Toplam İhracattaki } \\
\text { Pay }\end{array}$ & $\% 69.3$ & $\begin{array}{c}\text { Toplam İthalattaki } \\
\text { Pay }\end{array}$ & $\% 66.8$ \\
\hline
\end{tabular}

Türkiye'nin ihracat ve ithalatında ticarete en çok konu olan 5 ürün grubu Tablo 2'de yer almaktadır. Türkiye'nin ihracatının yaklaşık \%70'i tekstil, taşımacılık, makine, metaller ve değerli metal ve taşlar sektöründen oluşmaktayken, ithalatının yaklaşık \%67'si makine, metaller, taşımacılık, mineraller ve kimya sektöründen oluşmaktadır. Bu durum, Türkiye'nin ihracat ve ithalatındaki ürün çeşitliliğinin fazla olmadığını ve ticarete konu olan ürünlerin büyük çoğunluğunun aynı ürün grubundan oluştuğunu göstermektedir. 
İleri teknolojiye ve bilgi yoğunluğuna sahip ürünlerin üretiminde farklı alanlardan gelen bilgi birikimi ve teknolojileri birleştirmek gerekmektedir. Ülkenin bilgi kapasitesi, ürün çeşitlendirme ile doğrusal bir ilişkiye sahiptir. Buna ek olarak, ECI aynı zamanda ürünün üretici ülke sayısı ile de ilişkilidir. Tablo 3, üretim sektörlerini ve bu sektörlerin hangi ülkeler tarafından üretiminin yoğun olarak gerçekleştirildiğini göstermektedir.

Tablo 3. Üretim Sektörlerine Göre Ürünlerin Üreticileri

\begin{tabular}{cc}
\hline Ülkeler & Sektör \\
\hline Fransa & Otomobil, İlaç, Ham Petrol, Altın \\
\hline İsviçre & Altın, İlaç, Metal \\
\hline Hindistan & Rafine Petrol, Elmas \\
\hline Komorlar & Karanfil \\
\hline
\end{tabular}

Tablo 3 'te yer alan bilgilere göre, Fransa'nın çeşitlilik (diversity) skoru 4 iken, ilaç ve altın sektörünün sıradanlık (ubiquity) skoru 2'dir (Fransa ve İsviçre üretici ülkelerdir). Ülkeler ve ürünler için, ECI hesaplamasında ortalama sıradanlık ve ortalama çeşitlilik değerleri kullanılmaktadır. ECI hesaplamalarında yerli olarak üretilen ve ihraç edilen ürünleri dikkate alınmakta ve hizmetler hariç tutulmaktadır.

Tablo 4. En Yüksek ve En Düşük ECI Skoruna Sahip Ürünler

\begin{tabular}{cc}
\hline Ürün Grubu (SITC) & En Yüksek ECI Skorları \\
\hline Çeşitli Metal İşleme Tezgahları & 3.16 \\
\hline Epoksit Reçineleri & 2.89 \\
\hline Tekneler için İçten Yanmalı Motorlar & 2.85 \\
\hline Silikonlar & 2.49 \\
\hline Röntgen Cihazı & 2.42 \\
\hline Uranyum ve Toryum & En Düşük ECI Skorları \\
\hline Demir cevheri & -2.94 \\
\hline Susam Tohumu & -2.66 \\
\hline Bakır Cevherleri & -2.17 \\
\hline Ham Pamuk & -1.94 \\
\hline T'ten yüksk ve & -1.84 \\
\hline
\end{tabular}

Tablo 4'te en yüksek ve en düşük ECI skorlarına sahip ürün grupları yer almaktadır. En yüksek ECI skoruna sahip ürünler nitelikli işgücü gerektiren kimyasal ve makine grupları iken, en düşük ECI skoruna sahip ürünler hammaddeler veya temel tarım ürünleri olduğu görülmektedir. Ülkelerin ECI puanlarını arttırmaları için, ihraç edilen ürünlerin karmaşıklık seviyelerini ve ilgili sektördeki rekabet gücünü arttırmaları gerekmektedir.

\section{LITERATÜR TARAMASI}

Ülkelerin sürdürülebilir ekonomik koşullar oluşturabilmeleri ve uluslararası ticarette rekabet üstünlüğü elde edebilmeleri, ihracatlarındaki ürün çeşitliliği ve teknoloji yoğunluğuna dayanmaktadır. Ekonomik karmaşıklık endeksi, ülkelerin ihracatlarındaki bilgi yoğunluğunu ve ürün sofistikasyonunu ortaya koyan önemli bir göstergedir. Bu doğrultuda literatürde, ekonomik 
karmaşıklık endeksinin etkilediği ve etkilendiği koşullar üzerine bir takım çalışmalar yer almaktadır.

Ülkelerin rekabet edebilirliği ve ürün sofistikasyonu arasındaki ilişkiyi inceleyen Cristelli vd. (2013), klasik ticaret teorilerinin belirli endüstri dallarında uzmanlaşmalarını öngörmelerine rağmen gerçekte ülkelerin ihracatları incelendiğinde bu durumun beklenenden farklı olduğunu belirtmektedirler. Gelişmiş ülkelerin ihracatlarındaki ürün çeşitliliğinin fazla olduğunu ve basit düzeydeki ürünlerden karmaşı düzeye doğru geniş bir ürün yelpazesine sahip olduklarını ifade ederken, az gelişmiş ülkelerin ihracatlarının ise daha az ürün çeşitliliğine sahip olduğunu ve daha çok basit düzeydeki ürün yelpazesinden oluştuğunu ileri sürmektedirler.

Afrika ülkelerin ekonomik karmaşıklığını ölçmeyi hedefleyen Yamaego vd. (2014), Afrika ülkelerinin ihracatının teknoloji yoğunluğu, karşılaştırmalı üstünlükleri, ürün çeşitliliği, sıradanlık, ürün karmaşıklığı ile ilgili detaylı bilgiler içeren geniş bir veri tabanı oluşturmuştur. Gerçekleştirilen analizler sonucunda, Afrika ülkelerinin ekonomik karmaşıklıklarının düşük seviyede oldukları ve ihracatlarının oldukça az düzeyde çeşitlendirildiği ortaya koyulmuştur. $\mathrm{Bu}$ doğrultuda, Afrika ülkelerinin ekonomik karmaşıklıklarını arttırabilmeleri ve sürdürülebilir refah düzeyini sağlayabilmeleri için doğru makroekonomik politikaların oluşturulması gerektiği ileri sürülmektedir.

Gelişmiş ülkelerin yüksek düzeyde ekonomik karmaşıklığa sahip olduğunu belirten Akın ve Yildirimci (2015), bu ülkelerin ihracatta rekabet güçlerinin daha yüksek olduklarını belirtmektedir. Bu doğrultuda Türkiye'nin yüksek teknolojili ürün ihracatının payı göz önüne alındığında, Türkiye'nin gerektiği seviyenin altında olduğunu ifade etmişlerdir. Bu durum, nispeten düşük seviyedeki ekonomik karmaşıklık endeksine ve Türkiye'nin ihracatta rekabet üstünlüğü sağlamamasına neden olmaktadir.

Yerel kalkınmanın sağlanması için uygulanan politikaları ekonomik karmaşıklık analizi kapsamında inceleyen Arıcıoğlu vd. (2015), birbiriyle yakın olan bölgelerin sinıflandırılmasını ve potansiyel olarak hangi ürünlerin üretim ve ihracatını gerçekleştirebileceğini ortaya koymayı amaçlamışlardır. Analiz sonuçları doğrultusunda, İstanbul bölgesi (TR10) Türkiye'nin diğer bölgelerinden ayrışarak daha az sıradan, daha çok karmaşı ve nitelik olarak yüksek ürünlerin üretildiği bölge olduğu tespit edilmiştir. Bu noktada, teknoloji düzeyinin arttırılması hem nitelik olarak yüksek üretimi hem de daha fazla ürün çeşitliliği sağlayacaktır.

Ülkelerin ekonomik kalkınma düzeyini yönlendiren faktörün ekonomik karmaşıklık düzeyleri olduğunu belirten Inoua (2016), ekonomik refahı yüksek olan ülkelerin yüksek ürün çeşitliliğine sahip olduğunu ve sofistike ürünler ürettiklerini, ekonomik olarak az gelişmiş ülkelerin ise çok az ürün çeşitliliğine sahip olduğu ve karmaşı olmayan ürünler ürettiklerini ileri sürmektedir. Inoua (2016) çalışmanın amacını, ülkeler arasındaki gelir farklılıklarının büyük bir bölümünün ekonomik karmaşıklık endeksi ile açıklamak olarak belirtmiştir. Gerçekleştirilen analizle sonucunda, ekonomik karmaşıklık endeksi ve ülkeler 
arasındaki gelir farklılıkları arasında güçlü bir korelasyon (0.9) bulunduğu ortaya koyulmuştur.

Ekonomik karmaşıklığın ekonomik büyüme üzerindeki etkisini Avrupa Birliği ülkeleri kapsamında inceleyen Ertan Özgüzer ve Oğuş Binatlı (2016), analizleri sonuçlarında Avrupa Birliği'nde ekonomik karmaşıklığg belli bir eşiği aşan bir grup ülkenin ölçülen karmaşıklığına karşılık gelen gelir düzeylerine yakınlaşma eğiliminde olduğunu tespit etmişlerdir. Bununla birlikte, daha düşük karmaşıklık seviyesine sahip ülkelerde cari işlemler açığının ekonomik karmaşıklıkla etkileşimi ekonomik büyüme üzerinde önemli etkiye sahip olduğunu ortaya koymuşlardır.

Ülkelerin ihraç ettiği ürünlerin karmaşıklığına ilişkin verilerin bir ekonomide mevcut olan bilgiyi tahmin eden ve gelecekteki ekonomik büyümeyi öngören ekonomik karmaşıklık ölçütlerini oluşturmak için kullanıldığını belirten Albeaik vd. (2017), her bir ürünü ihraç etmenin zorluğunu ve bir ekonominin toplam ihracatını ölçen yeni ve daha basit bir ekonomik karmaşıklık ölçütü ortaya koymuşlardır. Ekonomilerin bilgi yoğunluğunu tahmin etmek ve gelecekteki ekonomik büyümeyi tahmin etmek için ortaya koyulan bu yaklaşım ile mevcut yöntemleri geliştirmişlerdir. Bu noktada, beşeri sermayeyi, politik istikrarı ve yolsuzluğun kontrolünün gelecekteki ekonomik büyüme ile pozitif ilişkili olduğu tespit etmişlerdir.

Ülkelerin sahip olduğu ortalama beceri seviyesini ölçmek amacıyla kullanılan ekonomik karmaşıklık endeksinin kişi başına gelir düzeyi ile ilişkisini araştıran Çeştepe ve Çağlar (2017), Türkiye'nin içerisinde olduğu 86 ülkenin verilerini kullanarak panel veri analizi gerçekleştirmişlerdir. Yapılan analizler sonucunda, kişi başına gelirin 20.395 ABD dolarından düşük olan ülkelerde ekonomik karmaşıklık endeksindeki artışın ekonomik büyümeyi olumlu etkilediği ve bu etkinin kişi başına gelirin artmasıyla azaldığı tespit edilmiştir. Türkiye özelinde elde edilen sonuçlar değerlendirildiğinde, ekonomik karmaşıklık endeksini arttırabilmek için sektörel dönüşümlerin sağlanması gerektiği ve yüksek katma değere sahip sektörlerin desteklenmesi gerektiğini ileri sürülmüştür.

Ekonomik karmaşıklık endeksi üzerinde teknoloji, ürün geliştirme ve ekonomik büyüme arasındaki ilişkiyi inceleyen Ivanova vd. (2017), ürün sofistikasyonu üzerindeki ilişkiyi teknoloji ve ürün geliştirme üzerine oluşturdukları endeksler üzerinden analiz etmiştir. Gerçekleştirilen analizler sonucunda, ekonomik karmaşıklık endeksi ile teknoloji ve ürün geliştirme üzerinde oluşturulan endeksler arasında önemli düzeyde korelasyon ilişkisi tespit edilmiştir. Bununla birlikte, dünyanın önde gelen ekonomilerinden Japonya'nın her üç göstergede de en yüksek puanlara ulaştığı, Çin'in ise ekonomik ve teknolojik karmaşıklığı birleştirmede giderek daha da başarılı olduğu tespit edilmiştir. $\mathrm{Bu}$ doğrultuda, teknolojik gelişme düzeyinin ve ürün geliştirme çalışmalarının ekonomik karmaşıklık endeksi üzerinde olumlu etkiler oluşturduğu ortaya koyulmuştur.

Türkiye'nin coğrafik bölgelerini ekonomik karmaşıklık analizi yardımıyla değerlendiren Tuncer vd. (2017), çalışmalarında bölgeler arasındaki farklı politika 
önerilerini ortaya koymayı hedeflemiş̧leridir. Bu doğrultuda, gerçekleşen üretim yapılarıyla ileriki dönemlerdeki ekonomik büyüme oranları arasındaki ilişki ekonomik karmaşıklık değişkenleri ile analiz edilmiştir. Çalışma sonucunda, Türkiye'de Marmara bölgesi, İzmir ve Ankara'nın ekonomik karmaşıklık değişkenleri olarak ele alınan teknolojik gelişme, ürün geliştirme ve nitelikli insan kaynağının bölgelerin ekonomik kalkınmaları için önemli rol oynadığı tespit edilmiştir.

Türkiye'nin ürün karmaşıklığ 1 ve reel efektif döviz kurunun diş ticaret hadlerine etkisini inceleyen Akın ve Güneş (2018), çalışmaları sonucunda ekonomik karmaşıklık endeksi, reel efektif döviz kuru ve dış ticaret haddi arasında istatistiksel olarak anlamlı ve pozitif yönlü bir ilişki bulunduğunu ortaya koymuşlardır. Bununla birlikte, ekonomik karmaşıklık endeksi ve reel efektif döviz kurundan diş ticaret haddine doğru tek yönlü nedensellik ilişkisi olduğu tespit edilmiştir.

Gelişmiş ülkelerde Ar-Ge çalışmalarına ve fikri mülkiyet haklarına atfedilen önemi vurgulayan Gaberli (2018), ekonomik karmaşıklık endeksi, fikri mülkiyet hakları ve Ar-Ge harcamaları ile yüksek teknoloji ihracatı arasındaki ilişkiyi incelemiştir. Çalışma kapsamında gerçekleştirilen panel veri analizi sonuçlarına göre, ekonomik karmaşıklık endeksi, Ar-Ge harcamaları ve fikri mülkiyet haklarına yapılan ödemeler ile yüksek teknoloji ihracatı arasında pozitif yönlü bir ilişkinin olduğu ortaya koyulmuştur.

Ekonomik karmaşıklık endeksini oluşturan unsurlar ile imalat ve ürün karmaşıklığının ekonomik büyümedeki önemli rolüne dikkat çeken Gala vd. (2018), ekonomik karmaşıklık endeksini kullanarak yoksul ve zengin ülkeler arasındaki yakınsama ve uzaklaşmayı açıklamak amacıyla ülkelerin ekonomik karmaşıklığının önemli olup olmadığını ve eğer öyleyse, gelir farkını azaltabilecek ülkelerin hangileri olduğunu doğrulamaya çalışmıştır. Çalışma sonucunda, ihracat ve üretim karmaşıklığının ülkeler arasındaki yakınsama ve uzaklaşmayı açıklamakta önemli faktörler olduğu ortaya koyulmuştur.

Ülkeler arasındaki ekonomik kalkınma ve ekonomik büyüme farklılıklarını açıklayabilmek için ekonomik karmaşıklık endeksinin önemli açıklamalar getirdiğini belirten Mealy vd. (2018), bölgesel farklılıkları ortaya çıkarma konusunda ekonomik karmaşıklık endeksini kullanmıştır. Çalışma sonucunda, özellikle gelişmekte olan ülkelerde yüksek teknolojili ürünlerin ihracatı, gelir artış1 ve ekonomik karmaşıklık endeksi arasında önemli bir ilişki olduğuna vurgu yapılmaktadır.

Ekonomik karmaşıklık endeksi ve ürün karmaşıklı̆̆ 1 endeksi olarak bilinen iki önemli endeksin ekonomik gelişme üzerinde önemli bilgiler sağladığını ileri süren Mealy (2019), gerçekleştirdikleri analizler sonucunda yüksek (düşük) ekonomik karmaşıklık endeksine sahip ülkelerin yüksek (düşük) ürün karmaşıklık endeksine sahip ürünlerde uzmanlaşma eğiliminde olduğunu tespit etmişlerdir.

Genel olarak ekonomik karmaşıklık endeksi üzerinde yapılan çalı̧̧malar değerlendirildiğinde, ekonomik karmaşıklık endeksi ile çeşitli ekonomik göstergeler arasındaki ilişkilerin sınandığı görülmektedir. Bununla birlikte, 
ekonomik karmaşılılı endeksi ile teknolojik gelişmelerin, ülkelerin gerçekleştirdiği yatırımların ve yüksek teknolojiye sahip ürünlerin ihracatları arasındaki ilişkilere değinen, ancak bu ilişkileri bir bütün içerisinde değerlendiren çalışmalar azınlıkta kalmıştır. Gerçekleştirilen bu çalışma ile ekonomik karmaşıklık endeksi üzerinde, Türkiye özelinde teknolojik gelişme, yüksek teknolojili ürün ihracatı ve sermaye yatırımlarının etkisi analiz edilerek literatüre özgün bir çalışma kazandırılmak istenmektedir.

\section{EKONOMETRİK ANALIZ}

$\mathrm{Bu}$ çalışmanın temel amacı, yüksek teknolojili ürün ihracatı, teknolojik gelişme ve brüt sabit sermaye yatırımlarının Türkiye'nin ekonomik karmaşıklık endeksi üzerindeki etkisini değerlendirmektir. Bu bağlamda, Türkiye'nin teknolojik gelişme performansının, sermaye yatırımlarının verimliliğinin ve katma değerli ürün ihracatının ihracat kompozisyonundaki ürün çeşitliliği üzerindeki yansımaları ortaya koyulacaktır. Böylece elde edilecek sonuçlar yardımıyla Türkiye'nin ihracatındaki ürün çeşitliliğini ve yüksek teknoloji içeren ürünlerin oranını arttırabilmesi amacıyla teknolojik gelişme, yüksek teknolojili ürün ihracatının ve sermaye yatırımlarının doğru yönlendirilmesi için önerilerde bulunulacaktır.

Teorik yaklaşımlar ve literatür araştırmaları doğrultusunda çalışma kapsamında, yüksek teknolojili ürün ihracatı, teknolojik gelişme ve brüt sabit sermaye yatırımlarının Türkiye'nin ekonomik karmaşıklık endeksi üzerindeki etkilerinin pozitif yönlü olması beklenmekte ve bu ilişkinin düzeyi incelenmektedir.

\section{A. Araştırma Modeli ve Veri Seti}

Bu çalışma ile 1989-2017 yılları arasındaki dönemde Türkiye'nin ECI skoru ile yüksek teknolojili ürün ihracatı, yerli patent başvuruları ve brüt sabit sermaye yatırımlarının arasındaki ilişki zaman serisi modelleri vasıtasıyla analiz edilmiştir.

Araştırmanın kurulan modellerinde bağımlı değişkenler olarak Türkiye'nin ECI skoru yer almıştır. Bağımsız değişkenler ise Türkiye'nin yüksek teknolojili ürün ihracatı, yerli patent başvuruları ve brüt sabit sermaye yatırımları modele dâhil edilmiştir. Türkiye'nin ekonomik karmaşıklık endeksine ilişkin veriler, Massachusetts Teknoloji Enstitüsü'ne bağlı Ekonomik Karmaşıklık Gözlemevi’ne (The Observatory of Economic Complexity) ait veri tabanından elde edilmiştir. Yüksek teknolojili ürün ihracatı, yerli patent başvuruları ve brüt sermaye yatırımlarına ilişkin veriler ise Dünya Bankası veri tabanından temin edilmiştir. Çalışmada kullanılan değişkenlere ait bilgiler şu şekildedir;

ECI : Türkiye'nin Ekonomik Karmaşıklık Endeksi

İHR : Türkiye'nin Yüksek Teknolojili Ürün İhracatı Düzeyi

PAT : Türkiye'nin Yerli Patent Başvuru Sayıları

YAT : Türkiye'de Gerçekleştirilen Brüt Sabit Sermaye Yatırımları

Bu bilgiler doğrultusunda, Türkiye ECI skoru ile yüksek teknolojili ürün ihracatı, yerli patent başvuruları ve brüt sabit sermaye yatırımları arasındaki 
ilişkinin analiz edilebilmesi amacıyla aşağıdaki zaman serisi modeli oluşturulmuştur;

$$
E C I_{t}=\beta_{0}+\beta_{1} \ln I H R_{t}+\beta_{2} \ln P A T_{t}+\beta_{3} \ln Y A T_{t}+\varepsilon_{t}(1)
$$

Model kapsamında; Türkiye'nin yüksek teknolojili ürün ihracatının, yerli patent başvuru sayılarının ve brüt sabit sermaye yatırımlarının doğal logaritması alınarak analizler gerçekleştirilmiştir. Araştırmanın hipotezi; Türkiye'nin yüksek teknolojili ürün ihracatının, yerli patent başvurularının ve sabit sermaye yatırımlarının yükselmesiyle, ülke ekonomisinde olumlu bir etki oluşarak ECI üzerinde pozitif yönde bir katkı sağlayacağı şeklindedir. Türkiye ECI skoru ile yüksek teknolojili ürün ihracat, yerli patent başvuruları ve brüt sabit sermaye yatırımları arasındaki ilişki zaman serisi analizi ile gerçekleştirilecektir. Ancak öncesinde zaman serilerinin durağanlığının test edilmesi ve düzeylerinde durağan olmayan serilerin durağanlaştırılmaları gerekmektedir.

\section{B. Analiz Sonuçları}

Zaman serisi analizlerinde değişkenler arasındaki eşbütünleşme analizini gerçekleştirebilmek için değişkenlerin durağan olmaları gerekmektedir. $\mathrm{Bu}$ doğrultuda, zaman serisi analizlerinin gerçekleştirilebilmesi amacıyla öncelikle değişkenlerin durağan olup olmadıkları, eğer durağan değil iseler hangi düzeyde durağan olduklarının saptanması gerekmektedir.

Zaman serisi analizi kapsamında ele alınan değişkenlerin durağanlığı, Genişletilmiş Dickey-Fuller (ADF) (Dickey ve Fuller, 1979-1981) testi ve PhilipsPerron (PP) (Philips ve Perron, 1988) birim kök testleri ile sınanmıştır. Genişletilmiş Dickey-Fuller (ADF) (2) testi ve Philips-Perron (PP) (3) testi sırasıyla aşağıda gösterilen modellere dayanmaktadır;

$$
\begin{gathered}
\Delta y_{t}=\alpha+\theta y_{t-1}+y_{1} \Delta y_{t-1}+\varepsilon_{\mathrm{t}} \\
\Delta y_{t-1}=\alpha_{t}+\lambda y_{t-1}+\varepsilon_{\mathrm{t}}
\end{gathered}
$$

Tablo 5. ADF Birim Kök Testi Sonuçları

\begin{tabular}{ccccc}
\hline \multirow{2}{*}{ Değişkenler } & \multicolumn{2}{c}{ ADF (Düzey) } & \multicolumn{2}{c}{ ADF (Birinci Fark) } \\
\cline { 2 - 5 } & Sabit & Sabit+Trend & \multicolumn{1}{c}{ Sabit } & Sabit+Trend \\
\hline ECI & -2.079 & -2.772 & $-7.081^{* * *}$ & $-7.017 * * *$ \\
\hline IHR & -0.851 & -2.038 & $-5.282^{* * *}$ & $-5.283^{* * *}$ \\
\hline PAT & 1.366 & -2.621 & $-4.438^{* * *}$ & $-4.583^{* * *}$ \\
\hline YAT & -1.106 & -2.701 & $-7.098^{* * *}$ & $-6.944 * *$ \\
\hline Not: $-* * *, * *$ ve $*$ siras1 ile $\% 1, \% 5$ ve $\% 10$ seviyesinde anlamlılığ1 ifade etmektedir. &
\end{tabular}

Genişletilmiş Dickey-Fuller birim kök testinin sıfır hipotezi "zaman serilerinin durağan olmadıkları (en az bir birim-kök var)" şeklindedir. Tablo 5 'te yer alan sonuçlara göre, serilerin düzeylerinde durağan olmadıkları, birinci farkları

\begin{tabular}{|c|c|c|c|c|}
\hline \multirow{2}{*}{ Değişkenler } & \multicolumn{2}{|c|}{ PP (Düzey) } & \multicolumn{2}{|c|}{ PP (Birinci Fark) } \\
\hline & Sabit & Sabit+Trend & Sabit & Sabit+Trend \\
\hline ECI & -1.517 & -1.741 & $-6.768 * * *$ & $-6.715^{* * *} *$ \\
\hline IHR & -0.745 & -2.038 & $-5.514 * * *$ & $-6.486^{* * *}$ \\
\hline PAT & 0.913 & -2.542 & $-4.434 * * *$ & $-4.583 * * *$ \\
\hline YAT & -1.032 & -2.751 & $-7.098 * * *$ & $-6.944 * * *$ \\
\hline
\end{tabular}
alındıktan sonra ise durağan hale geldikleri gözlemlenmektedir.

Tablo 6. PP Birim Kök Testi Sonuçları

Tablo 6'da Philips ve Perron (1988) birim kök testi sonuçları bulunmaktadır. Philips ve Perron (1988) birim kök testi sonuçları incelendiğinde, 
serilerin ADF birim kök testine paralel olarak düzeylerinde durağan olmadıkları, birinci fark düzeylerinde durağan hale geldikleri gözlemlenmektedir.

Seriler arasındaki durağanlığı bir yapısal kırılma altında inceleyen Zivot ve Andrews birim kök testi (1992), Türkiye'de meydana gelen yapısal kırılmalar ile serilerin test edilmesi amacıyla uygulanmıştır. Çalışma kapsamında Zivot ve Andrews birim kök testinin iki spesifikasyonu kullanılmıştır. Zivot \& Andrews (1992)'e göre model A, yalnızca sabitte yapısal kırılma ile birlikte durağanlığ ederken; model $\mathrm{C}$, hem sabitte hem de eğimde yapısal kırılma ile serilerin duranlığını test etmektedir;

$$
\begin{aligned}
& \text { Model } \mathrm{A} \Rightarrow \Delta Y_{t}=\beta_{1}+\beta_{2} t+\delta Y_{t-1}+\theta D U_{t}+\sum_{i=1}^{m} \alpha_{i} \Delta Y_{t-i}+\varepsilon_{t} \\
& \text { Model } \mathrm{C} \Rightarrow \Delta Y_{t}=\beta_{1}+\beta_{2} t+\delta Y_{t-1}+\theta D U_{t}+\gamma D T_{t}+\sum_{i=1}^{m} \alpha_{i} \Delta Y_{t-i}+\varepsilon_{t}
\end{aligned}
$$

Tablo 7. Zivot \& Andrews Yapısal Kırılmalı Birim Kök Testi Sonuçları

\begin{tabular}{cccccccc}
\hline \multirow{2}{*}{ Değişkenler } & \multicolumn{3}{c}{ Z\&A (Düzey) } & \multicolumn{3}{c}{ Z\&A (Birinci Fark) } & \multirow{2}{*}{ Model } \\
\cline { 2 - 6 } ECI & Kırılma Tarihi & $\mathbf{k}$ & Test İst. & Kırılma Tarihi & $\mathbf{k}$ & Test İst. & \\
\hline ECI & 2002 & 3 & -3.864 & 2012 & 0 & -8.344 & Model A \\
\hline IHR & 2005 & 1 & -2.606 & 2002 & 0 & -9.345 & Model C \\
\hline IHR & 1995 & 0 & -2.149 & 2002 & 1 & -7.465 & Model A \\
\hline PAT & 2003 & 8 & -4.267 & 2001 & 5 & -9.993 & Model C \\
\hline PAT & 1999 & 4 & -1.953 & 1998 & 0 & -5.311 & Model A \\
\hline YAT & 2003 & 1 & -3.964 & 2001 & 0 & -7.764 & Model A \\
\hline YAT & 2004 & 1 & -3.623 & 2001 & 0 & -8.502 & Model C \\
\hline \multirow{2}{*}{ Kritik Değerler } & \multicolumn{2}{c}{ Model A $=>\% 10:-4.1936 ; \% 5:-4.4436 ; \% 1:-4.9491$} & & \\
\hline
\end{tabular}

Tablo 7'de Zivot \& Andrews (1992) birim kök testi sonuçları yer almaktadır. Seriler üzerinde tek yapısal kırılma altında birim kök varlığını sınayan test sonuçlarına göre; ECI, IHR, PAT ve YAT değişkenlerinin bir yapısal kırılma ile birlikte hem model A hem de model C'de düzeyde durağan olmadıkları tespit edilmiştir. Serilerin birinci farkı alındığında, ; ECI, IHR, PAT ve YAT değişkenlerinin tek yapısal kırılma altında hem model A hem de model C'de birim kök içermedikleri, başka bir ifade ile durağan yapıda oldukları görülmüştür. Bununla birlikte, değişkenlerin Türkiye'de ve uluslararası ekonomide yaşanan önemli şokların değişkenler üzerinde etkili oldukları gözlemlenmiştir. Ekonomik karmaşıklık endeksinde model A'de 2002 ve model C'de 2012 tarihlerinde, yüksek teknolojili ürün ihracatında model A'da 2002 ve model C'de 2001 yıllarında, yerli patent başvurularında model A'da 1998 ve model C'de 2009 tarihlerinde, brüt sabit sermaye yatırımlarında ise hem model A'da hem de model C'de 2001 yilında yapısal kırılma yaşandığı tespit edilmiştir. Değişkenlere ait yapısal kırılma tarihleri incelendiğinde, Türkiye'nin ekonomik karmaşıklık endeksi, yüksek teknolojili ürün ihracatı, yerli patent başvuruları ve brüt sabit sermaye yatırımlarının ulusal ve uluslararası ekonomide yaşanan önemli şoklardan etkilendiğini göstermektedir.

Gerçekleştirilen yapısal kırılmalı birim kök testi sonucunda; ihraç edilen ürün çeşitliliğini gösteren ekonomik karmaşıklık endeksinde, Türkiye'de ekonomik krizlerin yaşandığı 2001 yılında ve Türkiye'nin en büyük ihracat pazarı olan Avrupa Birliği’ni derinden etkileyen 2011 Avrupa Borç Krizi’nin etkilerinin görüldüğü 2012 yılında yapısal kırılmaların meydana geldiği ortaya koyulmuştur. 
Tablo 8. Eşbütünleşme Test Sonuçları

Johansen Eşbütünleşme Testi Sonuçları

\begin{tabular}{|c|c|c|c|c|c|}
\hline $\mathbf{H}_{0}$ & İz Test İst. & Kritik Değer (\%5) & $\mathbf{H}_{0}$ & $\begin{array}{c}\text { Maksimum } \\
\text { Özdeğer İst. }\end{array}$ & Kritik Değer (\%5) \\
\hline $\mathbf{r}=\mathbf{0}$ & $75.828 * * *$ & 55.246 & $\mathbf{r}=\mathbf{0}$ & $46.374 * * *$ & 30.815 \\
\hline $\mathbf{r} \leq \mathbf{1}$ & 29.453 & 35.011 & $r=1$ & 22.445 & 24.252 \\
\hline $\mathbf{r} \leq \mathbf{2}$ & 7.008 & 18.398 & $\mathbf{r}=\mathbf{2}$ & 5.342 & 17.148 \\
\hline $\mathbf{r} \leq \mathbf{3}$ & 1.667 & 3.842 & $\mathbf{r}=\mathbf{3}$ & 1.667 & 3.842 \\
\hline \multicolumn{6}{|c|}{ Yapısal Kırılmalı Eşbütünleşme Testi } \\
\hline \multicolumn{2}{|c|}{ Gregory-Hansen Testi } & Test İstatistiği & $\mathbf{k}$ & & Kırılma Tarihi \\
\hline \multicolumn{2}{|c|}{ ADF* } & -6.42 & 0 & & 2013 \\
\hline \multicolumn{2}{|c|}{$\mathbf{Z t}^{*}$} & -6.54 & 0 & & 2013 \\
\hline \multicolumn{2}{|c|}{$\mathbf{Z a}^{*}$} & -34.66 & 0 & & 2013 \\
\hline
\end{tabular}

Not: - ***, \%1 seviyesinde anlamlılığı ifade etmektedir. Gregory-Hansen (1996) Eşbütünleşme testi kritik değerleri $\% 1, \% 5$ ve $\% 10$ için sırasıyla, $\mathrm{ADF}^{*}$ ve $\mathrm{Zt}^{*}-5.77,-5.28$ ve -5.02 ; $\mathrm{Za}^{*}-63.64,-53.58$ ve -48.65 olarak hesaplanmıștır.

Tablo 8'de yer alan Johansen (1990) eşbütünleşme test sonuçları doğrultusunda ve iz testi ve maksimum özdeğer testi istatistiklerine göre, ekonomik karmaşıklık endeksi, yerli patent başvuruları, yüksek teknolojili ürün ihracatı ve brüt sabit sermaye yatırımları arasında en az bir eşbütünleşme vektörünün bulunduğu tespit edilmiştir. Bununla birlikte bir yapısal kırılmaya izin veren Gregory-Hansen (1996) eşbütünleşme testi sonuçlarına göre, test istatistikleri $\left(\mathrm{ADF}^{*}\right.$ ve $\mathrm{Zt}^{*}$ ) değişkenler arasında bir yapısal kırılma varlığında \%1 anlamlılık düzeyinde eşbütünleşme ilişkisinin bulunduğu görülmüştür. $\mathrm{Bu}$ doğrultuda, ekonomik karmaşıklık endeksi, yerli patent başvuruları, yüksek teknolojili ürün ihracatı ve brüt sabit sermaye yatırımları arasında uzun dönemli bir ilişsinin bulunduğu gözlemlenmiştir. Johansen eşbütünleşme testi ve Gregory-Hansen eşbütünleşme testi sonuçları birbiri ile tutarlı sonuçlar vermektedir. Ayrıca, Gregory-Hansen eşbütünleşme testine göre 2013 yılında yaşanan yapısal kırılma önemli bir göstergedir. İlgili tarihi içeren süreç ve öncesinde yaşanan 2008 küresel ekonomik krizinin ve 2011 yılında ortaya çıkan Avrupa Borç Krizi'nin etkilerinin Türkiye'nin ihracatında, sabit sermaye yatırımlarında ve teknolojik gelişiminde önemli etkiler yarattığı tespit edilmiştir.

Tablo 9. Uzun Dönem Katsayı Tahmin Sonuçları

\begin{tabular}{cccc}
\hline Bağımlı Değişken & \multicolumn{3}{c}{ DOLS } \\
\hline ECI & Katsayı & Standart Hata & T İstatistiği \\
\hline IHR & 0.278 & 0.051 & $5.422^{* * *}$ \\
\hline PAT & 0.325 & 0.091 & $3.598^{* * *}$ \\
\hline YAT & 0.233 & 0.103 & $2.251^{* *}$ \\
\hline C & -12.019 & 1.968 & $-6.107^{* * *}$ \\
\hline Not: $-* * *, * *$ ve * sirası ile $\% 1, \% 5$ ve $\% 10$ seviyesinde anlamlllı̆̆ ifade etmektedir.
\end{tabular}

Model kapsamında değişkenler arasında uzun dönemli ilişkinin varlığının tespiti sonrasında, uzun dönemli ilişkiye sahip olan değişkenlerin parametre tahminleri otokorelasyon ve içsellik sorunları bulunması halinde dahi güçlü tahminler ortaya koyan Dinamik En Küçük Kareler (DOLS) yöntemi kullanılarak 
gerçekleştirilmiştir. Çalışma kapsamında değişkenlerin uzun dönemli katsayı tahmini sonuçları Tablo 9'da yer almaktadır. Türkiye'nin ekonomik karmaşıklık endeksinin tahmini için oluşturulan modelin uzun dönemli katsayı tahmini sonucunda; Türkiye'de gerçekleştirilen yüksek teknolojili ürün ihracatının, teknolojik gelişme düzeyinin ve sabit sermaye yatırımlarının Türkiye'nin ihracatındaki ürün sofistikasyonu üzerinde pozitif ve istatistiki olarak anlamlı sonuçlar verdiği görülmüştür. Uzun dönemde Türkiye'de yüksek teknolojili ürün ihracatının \%1 düzeyinde artması, Türkiye'nin ihracatındaki ürün çeşitliliğini $\% 0.28$ düzeyinde yükselttiği tespit edilmiştir. Ayrıca, Türkiye'de teknolojik gelişme düzeyinin $\% 1$ yükselmesinin Türkiye'nin ihracatındaki ürün sofistikasyonunu \%0.33 düzeyinde arttırdığ1 görülmüştür. Son olarak, Türkiye'de gerçekleştirilen sabit sermaye yatırımlarının \%1 artması ekonomik karmaşıklık endeksi üzerinde uzun dönemde $\% 0.23$ seviyesinde yükselttiği ortaya koyulmuştur.

Seriler arasında eşbütünleşme ve uzun dönemli ilişkinin tespit edilmesi durumunda, seriler arasında en az bir yönde nedensellik ilişkisnin varlığ beklenmektedir. Seriler arasındaki nedensellik ilişkisinin yönünü ortaya koymak amaciyla Granger (1986) ve Engle-Granger (1987) tarafından geliştirilen nedensellik testi yapılmıştır.

Tablo 10. VEC Granger Nedensellik Test Sonuçları

\begin{tabular}{ccc}
\hline H0 Hipotezi & Wald $\chi^{2}$ Test İst. & Nedensellik İlişkisi \\
\hline ECI $\neq>$ IHR & $6.297^{*}$ & Var \\
\hline ECI $\neq$ PAT & $9.594^{* *}$ & Var \\
\hline ECI $\neq>$ YAT & 5.216 & Yok \\
\hline IHR $\neq>$ ECI & $8.468^{* *}$ & Var \\
\hline IHR $\neq>$ PAT & $8.499^{* *}$ & Var \\
\hline IHR $\neq>$ YAT & 3.479 & Yok \\
\hline PAT $\neq>$ ECI & $12.444^{* * *}$ & Var \\
\hline PAT $\neq>$ IHR & $6.459^{*}$ & Var \\
\hline PAT $\neq>$ YAT & 1.023 & Yok \\
\hline YAT $\neq>$ ECI & $12.651^{* * *}$ & Var \\
\hline YAT $\neq>$ IHR & $18.929^{* * *}$ & Var \\
\hline YAT $\neq>$ PAT & $25.936^{* * *}$ & Var \\
\hline Not $-* * * * *$
\end{tabular}

Not: - ***, ** ve * siras1 ile \%1, \%5 ve \%10 seviyesinde anlamlılı̆̆ ifade etmektedir.

Değişkenler arasındaki uzun dönemli ilişkinin belirlenmesi sonrasında, değişkenler arasındaki nedensellik ilişkileri analiz edilmiştir. Ekonomik karmaşıklık endeksi, yüksek teknolojili ürün ihracatı, yerli patent başvuruları ve brüt sabit sermaye yatırımları arasındaki nedensellik ilişkisi Tablo 10'da yer almaktadır. Sonuçlara doğrultusunda; ekonomik karmaşıklık endeksi, yüksek teknolojili ürün ihracatı ve yerli patent başvuruları arasında çift yönlü bir nedensellik ilişkisi olduğu görülmüştür. Bununla birlikte, brüt sabit sermaye yatırımlarından ekonomik karmaşıklık endeksi, yüksek teknolojili ürün ihracatı ve yerli patent başvurularına doğru tek yönlü bir nedensellik ilişkisi bulunduğu ortaya koyulmuştur. 
Şekil 1. Değişkenler Arasındaki Nedensellik İlişkileri

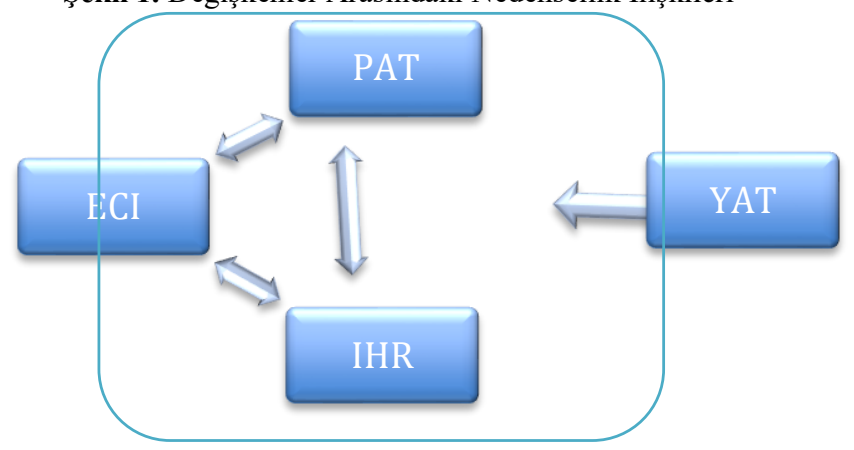

Değişkenler arasındaki nedensellik ilişkileri değerlendirildiğinde, Türkiye'de gerçekleştirilen sabit sermaye yatırımlarının arttırılması ile yüksek teknolojili ürün ihracatının ve teknolojik gelişme düzeyinin yükseltilebileceği, dolayısıyla Türkiye'nin ihracattaki ürün çeşitliliğinin arttırılabileceği tespit edilmiştir. Bununla birlikte ekonomik karmaşıklık endeksi, yerli patent başvuruları ve yüksek teknolojili ürün ihracatının karşılıklı nedensellik ilişkilerine sahip olması, Türkiye'nin teknolojik altyapısının geliştirilmesi hem sahip olunan teknolojik gelişme seviyesinin hem de ihracatta yüksek teknolojili ürün ihracatının arttırılarak ürün çeşitliliğinin yükseltilebileceğini göstermektedir.

\section{SONUÇ}

Ülkelerin ihracat kompozisyonlarındaki ürün çeşitliliğini ve bilgi yoğunluğu ortaya koyan ekonomik karmaşıklık endeksi, ülkelerin uluslararası rekabette var olabilmelerine ve bu rekabeti sürdürülebilir kılmalarını ortaya koyabilmek için önemli bir göstergedir. Ülkeler ihracatlarındaki ürün çeşitliliğini arttırabilmek için araştırma ve geliştirme faaliyetlerini yoğunlaştırmakta ve sabit sermaye yatırımlarını bu doğrultuda yönlendirmektedirler. Gerçekleştirilen teknolojik gelişmeler ile birlikte ülkelerin ihracatlarındaki yüksek teknolojili ürün payı yükselmekte, böylelikle hem uluslararası rekabet üstünlügü elde edilebilmekte hem de ihracatlarındaki ürün çeşitliliği artmaktadır.

Çalışma kapsamında, Türkiye'nin yüksek teknolojili ürün ihracatı, teknolojik gelişme düzeyi ve sermaye yatırımlarının Türkiye'nin ekonomik karmaşıklık endeksi üzerindeki etkileri analiz edilmiştir. Bu doğrultuda ilk olarak, Türkiye'nin yüksek teknolojili ürün ihracatı, yerli patent başvuruları ve brüt sabit sermaye yatırımları ile Türkiye'nin ekonomik karmaşıklık endeksi arasındaki uzun dönemli ilişkiler Johansen ve Gregory-Hansen yapısal kırılmalı eşbütünleşme analizleri vasıtasıyla incelenmiştir. Gerçekleştirilen analizler sonucunda, değişkenler arasında uzun dönemli bir ilişkinin varlığ 1 tespit edilmiştir. Başka bir ifade ile Türkiye'nin yüksek teknolojili ürün ihracatı, teknolojik gelişme düzeyi ve sermaye yatırımları ile ekonomik karmaşıklık endeksi arasında uzun dönemli bir ilişskinin bulunduğu ortaya koyulmuştur.

Değişkenler arasındaki uzun dönemli ilişkilerin tespit edilmesi sonrasında, uzun dönemde ekonomik karmaşılık endeksi ile yüksek teknolojili ürün ihracatı, 
yerli patent başvuruları ve brüt sabit sermaye yatırımları arasındaki katsayı ilişkisi dinamik en küçük kareler yöntemiyle analiz edilmiştir. Analizler sonucunda, Türkiye'nin yüksek teknolojili ürün ihracatının \%1 düzeyinde yükselmesi ekonomik karmaşıklık endeksini \%0.28 düzeyinde attırmaktadır. Bununla birlikte, teknolojik gelişme düzeyindeki \%1'lik artış ekonomik karmaşıklık endeksini $\% 0.33$ düzeyinde arttırırken, sabit sermaye yatırımlarındaki \%1 düzeyindeki yükselme ise ekonomik karmaşıklık endeksini \%0.23 düzeyinde arttırmaktadır.

Uzun dönem katsayı tahminlerinin ardından gerçekleştirilen nedensellik analizleri sonucunda, ekonomik karmaşıklık endeksi, yerli patent başvuruları ve yüksek teknolojili ürün ihracatı arasında iki yönlü nedensellik ilişkilerinin bulunduğu görülürken, sabit sermaye yatırımlarından ekonomik karmaşıklık endeksine, yerli patent başvurularına ve yüksek teknolojili ürün ihracatına doğru tek yönlü bir nedensellik ilişkisinin var olduğu tespit edilmiştir. Elde edilen bulgular doğrultusunda, Türkiye'de gerçekleştirilen sabit sermaye yatırımlarının yüksek teknolojili üretim gerçekleştirilebilecek sektörlere yönlendirilmesinin büyük önem arz ettiği görülmüştür. Yüksek teknolojili ürün üretiminin ve yeni teknolojik gelişmelerin gerçekleştirilebileceği alanlara yapılacak sermaye yatırımları vasıtasıyla Türkiye'nin ekonomik karmaşıklık endeksinin daha da arttırılabileceği ortaya koyulmuştur. $\mathrm{Bu}$ doğrultuda, Türkiye'de ekonomi politikalarının ve yatırımların yüksek katma değere sahip ve teknolojik bilginin yoğun olduğu üretim alanlarına yönlendirilmesi ile birlikte ihracatta ürün çeşitliliğinin arttırılabileceği ve uluslararası rekabet üstünlügünün uzun dönemde sağlanabileceği tespit edilmiştir

\section{KAYNAKÇA}

Akın, T. ve Güneş, S. (2018). İhracatın Niteliğindeki Artışın Dış Ticaret Haddine Etkisi: Türkiye Analizi. C.Ü. İktisadi ve İdari Bilimler Dergisi 19(2): 448-462.

Albeaik, S., Kaltenberg, M., Alsaleh, M. ve Hidalgo, C. A. (2017). Improving the Economic Complexity Index. arXiv:1707.05826.

Ang, J. B., Madsen, J. B. ve Robertson, P. E. (2015). Export Performance of the Asian Miracle Economies: The Role of Innovation And Product Variety. The Canadian Journal of Economics 48(1): 273-309.

Arıcıoğlu, E., Coşkun, N. ve Tuncer, İ. (2017). Tasarruf, Sürdürülebilir Büyüme ve Teknolojik Gelişme. O. S. Erdoğdu, D. T. Dinç ve M. A. Atar (ed.), Türkiye'de İBBS Düzey 2 Bölgelerinin Büyüme Dinamikleri ve Ekonomik Karmaşıklık Analizi Dâhilinde (s. 59-90), Ankara: Türkiye Ekonomi Kurumu.

Cristelli, M., Gabrielli, A., Tacchella, A., Caldarelli, G. ve Pietronero, L. (2013). Measuring the Intangibles: A Metrics for the Economic Complexity of Countries and Products. PLoS ONE $8(8): 1-20$.

Çeştepe, H. ve Çağlar, O. (2017). Ürün Sofistikasyonu ve Ekonomik Büyüme İlişkisi: Panel Veri Analizi. Uluslararası Yönetim İktisat ve İşletme Dergisi, ICMEB17 Özel Sayısı, 992-1000.

Çetin, R. (2016). Yeni Sanayileşen Ülkelerde Ar-Ge Harcamaları ve Yüksek Teknoloji Ürünü İhracatı Arasındaki İlişkinin Panel Veri Analizi Yöntemi ile İncelenmesi. İktisat Fakültesi Mecmuas1 66(2): 30-43.

Çütçü, İ. (2017). İnovasyonun İhracat Performansına Etkisi: Yatay-Kesit Analizi Uygulaması. Uluslararası Sosyal Araştırmalar Dergisi 10(48): 586-596.

Di Pietro, W. R. ve Anoruo, E. (2006). Creativity, Innovation, and Export Performance. Journal of Policy Modeling 28: 133-139. 
Dickey, D. A. ve Fuller, W. A. (1979). Distribution Of The Estimators For Autoregressive Time Series With A Unit Root. Journal of the American Statistical Association 74(366): 427 - 431.

Dickey, D. A. ve Fuller, W. A. (1981). Likelihood Ratio Statistics for Autoregressive Time Series with a Unit Root. Econometrica, 49: 1057-1063.

Engle, R. F. ve Granger, C. W. J. (1987). Co-integration and Error Correction: Representation, Estimation, and Testing. Econometrica 55: $251-276$.

Erkan, B. ve Yildirimci, E. (2015). Economic Complexity and Export Competitiveness: The Case of Turkey. Procedia - Social and Behavioral Sciences 195: 524-533.

Ertan Özgüzer, G. ve Oğuş Binatlı, A. (2016). Economic Convergence in the EU: A Complexity Approach. Eastern European Economics 54: 93-108.

Falvey, R. (1981). Commercial Policy And Intra-Industry Trade. Journal of International Economics 11(4): 495-511.

Falvey, R. ve Kierzkowski, H. (1987). Product Quality, Intra-industry Trade and (Im)perfect Competition. H. Kierzkowski (ed.), Protection and Competition in International Trade Dâhilinde (s. 143-161), Basil-Blackwell.

Flam, H. ve Helpman, E. (1987). Vertical Product Differentiation and North-South Trade. The American Economic Review 77(5): 810-822.

Gaberli, Ü. (2018). G7 Ülkelerinde Fikri Mülkiyet Haklarına Yapılan Ödemeler ve Ar-Ge Harcamalarının Yüksek Teknoloji İhracatına Etkisi: Bir Panel Veri Analizi. Finans Politik \& Ekonomik Yorumlar (641): 67-82.

Gala, P., Rocha, I. ve Magacho, G. (2018). The Structuralist Revenge: Economic Complexity as an Important Dimension to Evaluate Growth and Development. Brazilian Journal of Political Economy 38(2): 219-236.

Granger, C. W. J. (1986). Developments in The Study of Cointegrated Economic Variables. Oxford Bulletin of Economics and Statistics 48(3): 213 - 228.

Gregory, A. W. ve Hansen, B. E. (1996). Residual-based Tests for Cointegration in Models with Regime Shifts. J. Econometrics 70: 99-126.

Hidalgo, C. A. ve Hausmann, R. (2009). The Building Blocks of Economic Complexity. PNAS 106(26): 10570 - 10575.

Inoua, S. (2016). A Simple Measure of Economic Complexity. Statistical Finance, 1-15.

Ivanova, I., Strand, Ø., Kushnir, D. ve Leydesdorff, L. (2017). Economic and Technological Complexity: A Model Study of Indicators of Knowledge-Based Innovation Systems. Technological Forecasting \& Social Change 120: 77-89.

Johansen, S. ve Juselius, K. (1990). Maximum Likelihood Estimation and Inference on Cointegrationwith Application to the Demand for Money. Oxford Bulletin of Economics and Statistics 52: $169-210$.

Mealy, P., Farmer, J. D. ve Teytelboym, A. (2018). A New Interpretation of the Economic Complexity Index. SSRN Electronic Journal, 1 -22.

Phillips, P. C. B. ve Perron, P. (1988). Testing for a Unit Root in Time Series Regression. Biometrika 75(2): $335-346$.

Şahbaz, A., Yanar, R. ve Adıgüzel, U. (2014). Ar-Ge Harcamaları ve İleri Teknoloji Mal İhracatı İlişkisi: Panel Nedensellik Analizi. Ç.Ü. Sosyal Bilimler Enstitüsü Dergisi 23(1): 47-60.

Tekin, E. ve Hancıŏlu, Y. (2018). İnovasyon Belirleyicilerinin İhracat Performansına Etkisi Üzerine Bir Araştırma. Uluslararası Yönetim İktisat ve İşletme Dergisi 14(4): 897-917.

Tuncer, İ., Lopcu, K., Coşkun, N. ve Arıcıoğlu, E. (2017). Türkiye Bölgelerinde Yapısal Değişim: Kümeleme ve Ekonomik Karmaşıklık Analizleri Bağlamında Öneriler. Ekonomi Bilimleri Dergisi 9(2): 59-74.

Yamaego, N. D., Nabassaga, T., Shimeles, A. ve Ncube, M. (2014). Diversification and Sophistication as drivers of structural transformation for Africa: The Economic Complexity Index of African Countries. Journal of African Development 16(2): 1-31.

Yıldırım, E. ve Kesikoğlu, F. (2012). Ar-Ge Harcamaları ile İhracat Arasındaki Nedensellik İlişkileri: Türkiye Örneğinde Panel Nedensellik Testi Kanıtları. Marmara Üniversitesi İ.İ.B.F. Dergisi 32(1): 165-180. 
Zivot, E. ve Andrews, D. W. K. (1992). Further Evidence On The Great Crash, The Oil Price Shock

Ans Unit Root Hypothesis. Journal of Business \& Economic Statics 10(3): 251 - 270.

\section{SUMMARY}

Determining sectors invested in is greatly important for countries to gain competitive advantages in international trade. In order to gain comparative advantage in international trade, countries need to determine which sector to invest in and which sectors will intensify their research and development activities. Especially with the increasing global trade volume, countries have become more dependent on international trade to achieve sustainable economic growth and increase their level of development.

Increasing the share of value-added and high-tech product exports in total exports are based on the density and efficiency of the research and development activities for the countries. In this respect, countries should invest in high technology sectors in which they can gain comparative advantage in order to be successful in international competition. Associated with the technological advances, the range of high technology and value-added products in exports will be expanded by providing international competitive advantage. This situation will enable countries to gain comparative advantage in global trade.

The economic complexity index measures the information on intensity and productive output of an economy by considering the information intensity of products exported by a country. The complexity of an economy is related to the abundance of useful information contained therein. Economic complexity can be measured by the composition of products countries can produce.

In the study, the relationships among high-tech product exports, gross capital formation and economic complexity index which is reveal technological development and comparative advantage is analyzed in Turkey. Long-term relationships among the variables are analyzed by Johansen and Gregory-Hansen cointegration tests. As a result of cointegration analysis, long-term relationships between economic complexity index, resident patent applications, high-tech product exports and gross fixed capital investments are observed. Johansen and Gregory-Hansen cointegration test results are consistent with each other. In addition, a structural break in 2013 according to Gregory-Hansen cointegration test is determined. In this direction, global economic crisis in 2008 and European debt crisis in 2013 have important effects on fixed capital investment, technological development and exports of Turkey.

In direction with results of estimating long-term coefficient, high-tech exports, technological developments and fixed capital investment have positive and statistically significant results on economic complexity index of Turkey. 1\% increase of exports of high-tech products in Turkey raises the range of export products of Turkey by $0.28 \%$ in the long-term. Moreover, $1 \%$ increase in the level of technological development in Turkey increases product sophistication by $0.33 \%$ of Turkey's exports in the long-term. It is revealed that $1 \%$ increase in fixed capital 
investment in Turkey procures the increment in the economic complexity index by $0.23 \%$ of Turkey in the long-term.

After determining long-term relationship among variables, causality relationships between variables are analyzed. As a result of causality analysis, bidirectional causality relationships between economic complexity index, hightech product exports and resident patent applications is seen. On the other hand, unidirectional causality relationships from gross fixed capital investments to economic complexity index, high-tech product exports and resident patent applications has been observed.

When assessing causal relationships among the variables, it is detected that level of technological developments, high-tech exports and economic complexity index of Turkey can be increased along with the more fixed capital investments. In addition to this, causality relationship between resident patent applications and high-tech exports shows that technological developments have increased economic complexity index as well as high-tech exports. 